\title{
Short communication: Characterization of enterotoxin-producing Staphylococcus aureus isolated from mastitic cows
}

\author{
Luca Grispoldi, ${ }^{1 *}$ Luca Massetti, ${ }^{1}$ Paola Sechi, ${ }^{1}$ Maria F. Iulietto, ${ }^{1}$ Margherita Ceccarelli, ${ }^{1}$ Musafiri Karama, ${ }^{2}$ \\ Paul A. Popescu, ${ }^{3}$ Francesco Pandolfi, ${ }^{4}$ and Beniamino T. Cenci-Goga ${ }^{2} \dagger$ \\ ${ }^{1}$ Department of Veterinary Medicine, Laboratorio di Ispezione degli alimenti di origine animale, University of Perugia, Perugia, 06126 , Italy \\ ${ }^{2}$ Faculty of Veterinary Science, Department of Paraclinical Sciences, University of Pretoria, Onderstepoort, 0110, South Africa \\ ${ }^{3}$ Faculty of Biotechnology, University of Agronomic Science and Veterinary Medicine, Bucharest, 011464, Romania \\ ${ }^{4}$ Azienda Unità Sanitaria Locale Umbria n. 2, Umbria, 06034, Italy
}

\section{ABSTRACT}

Staphylococcus aureus is not only a common cause of bovine mastitis, but also an agent of food poisoning in humans. In an attempt to determine whether staphylococci causing bovine mastitis could also cause food poisoning, 60 isolates of presumed $S$. aureus were isolated in the period between March and August 2017 from 3,384 routine, composite, quarter milk samples of individual cows raised on 12 dairy farms in central Italy. Seventeen out of 60 isolates were confirmed as $S$. aureus after coagulase, thermonuclease, and biochemical tests. These isolates were analyzed by PCR for the presence of the $n u c$, sea, seb, sec, sed, and see genes. The positive isolates were nuc, $100 \%$ (17); sea, $35.29 \%$ (6); seb, $5.88 \%$ (1); sec, $5.88 \%$ (1); sed, $29.41 \%$ (5); and see, $47.06 \%$ (8). The isolates were also tested with 2 enzyme immunoassay diagnostic kits, one for the screening detection of the production of staphylococcal enterotoxins (SEA, SEB, SEC, SED, SEE) and one for the detection of specific enterotoxin produced by each isolate. Seven out of $17(41.18 \%)$ were enterotoxin producers: 7 produced SEA (41.18\%), 1 SEB (5.88\%), 1 SEC (5.88\%), 5 SED $(29.41 \%)$, and 6 SEE $(35.29 \%)$. To further characterize the isolates, they were analyzed by the Kirby Bauer test for susceptibility to 13 antimicrobials (ampicillin, ciprofloxacin, kanamycin, tetracycline, gentamicin, methicillin, nalidixic acid, erythromycin, amoxicillin/ clavulanic acid, streptomycin, vancomycin, neomycin, and enrofloxacin), and we detected resistance to ampicillin (52.94\%), nalidixic acid (70.59\%), erythromycin (5.88\%), and amoxicillin/clavulanic acid (17.65\%). The isolates were sensitive to the main classes of antimi-

Received July 12, 2018.

Accepted November 6, 2018.

*Corresponding author: grisluca@outlook.it

$\dagger$ Present address: Department of Veterinary Medicine, Laboratorio di Ispezione degli alimenti di origine animale, University of Perugia, Italy. crobials used for the treatment of bovine subclinical mastitis. The presence of enterotoxin-producing isolates of $S$. aureus in bovine milk means that a temperature abuse or a breakdown in the thermal treatment of the milk could present a food safety risk, particularly if all enterotoxigenic isolates could potentially produce SEA in milk.

Key words: Staphylococcus aureus, mastitis, enterotoxin, food poisoning

\section{Short Communication}

Staphylococcus aureus is an opportunistic pathogen and is a common bacterial cause of mastitis in cows and a cause of food-borne disease in humans. The European Food Safety Authority registered 434 reported staphylococcal food poisoning outbreaks in 2015, which equals over half of all food-borne outbreaks associated with bacterial toxins (European Food Safety Agency and European Centre for Disease Prevention and Control, 2016). In the United States, the Centers for Disease Control estimate that 240,000 cases of staphylococcal food poisoning occur each year, leading to 1,000 hospitalizations and 6 fatalities (Schelin et al., 2017). Food poisoning caused by $S$. aureus is related to the production of staphylococcal enterotoxins (SE), which act on specific, emetic receptors located in the intestinal wall. Enterotoxins are short, water-soluble, extracellular proteins. To date, 23 distinct SE have been identified based on their antigenicity (SEA to SEIY; Denayer et al., 2017). Only one subset of SE possess emetic activities (Ono et al., 2015). Of the 23 SE identified and reported in literature, only 5 (SEA, SEB, SEC, SED, and SEE) have been well defined and are detectable using commercially available assays or in-house developed methods (Nia et al., 2016). In addition to emetic SE, multiple SE-like toxins (SEl) have been reported, which lack the ability to cause emesis or for which the emetic potential remains to be tested (Hait et al., 2014). 
Therefore, their role in staphylococcal food poisoning remains unclear. Due to their stability at high temperatures (for instance, crude enterotoxin A remains active at $100^{\circ} \mathrm{C}$ for $2 \mathrm{~h}$ in broth and at $121^{\circ} \mathrm{C}$ for $28 \mathrm{~min}$ in mushrooms), SE are not completely destroyed during pasteurization $\left(15 \mathrm{~s}\right.$ at $\left.72^{\circ} \mathrm{C}\right)$ and are considered to be a potential biological hazard (Hennekinne et al., 2012). In addition, SE are resistant to many environmental conditions (low $\mathrm{pH}$, freezing, drying) in which $S$. aureus strains do not survive. They are also resistant to human proteolytic enzymes and retain their activity in the digestive tract after ingestion (Hennekinne et al., 2012). The amount of enterotoxin required to cause the illness in susceptible subjects can be as little as 20 to $100 \mathrm{ng}$ (Asao et al., 2003).

Many outbreaks of $S$. aureus food poisoning have been related to the consumption of dairy products, such as cheese from unpasteurized milk (Ostyn et al., 2010), semihard cheese (Kérouanton et al., 2007), or milk powder (Ikeda et al., 2005). Symptoms in humans vary and their severity depends on the amount of food ingested, the amount of toxin in the ingested food, and the patient's general state of health. The disease is characterized mainly by vomiting, diarrhea, abdominal pain, and nausea, with an onset within 2 to $6 \mathrm{~h}$ after the consumption of contaminated food (Cenci-Goga et al., 2003). Ingested bacteria do not produce toxins and, therefore, the symptoms normally wear off within $24 \mathrm{~h}$. The ability of $S$. aureus strains to cause food poisoning has mainly been investigated by techniques of molecular biology. Numerous studies indicated that stress conditions, such as milk $\mathrm{pH}$ and temperature, might influence the expression of genes that code for the production of enterotoxins (Schelin et al., 2017). Therefore, despite the large number of works describing the prevalence of enterotoxin gene profiles from clinical and environmental S. aureus (Ono et al., 2015; Denayer et al., 2017), information on the actual ability of strains responsible for mastitis to produce $\mathrm{SE}$ is scarce. In the present study, we tested 60 isolates of presumed $S$. aureus isolated from mastitic cows for the production of enterotoxins SEA, SEB, SEC, SED, and SEE in an attempt to explore their potential to cause food poisoning in humans.

Milk sampling was carried out between March and August 2017 in dairy farms pertaining to Unità Sanitaria Locale 2 Foligno, in central Italy. A total of 1,232 heads of cattle were hosted on the 12 farms examined, 564 of which were in lactation at the time of sampling. A total of 128 samples were taken from 87 cows with a high number of somatic cells in milk. These subjects were chosen based on data from the provincial breeders' association (APA, Corciano, Perugia, Italy), which monitors the farms and reports the data. The composite quarter milk of individual mastitic cows were collected in sterile tubes and transported to the laboratory in a refrigerated container.

We carried out the culture and identification of $S$. aureus according to the methods described by the ISO standard 6888-1:1999 (ISO, 1999). First, $1 \mathrm{~mL}$ of each milk sample was diluted in a sterile tube containing 9 $\mathrm{mL}$ of Maximum Recovery Diluent (Oxoid, Basingstoke, UK) to obtain a 10 -fold dilution. Subsequently, $0.1 \mathrm{~mL}$ of raw milk and the 10-fold dilutions were inoculated in triplicate on the surface of plates containing Baird Parker agar (Liofilchem, Roseto degli Abruzzi, Italy) prepared with the addition of egg yolk tellurite emulsion (Liofilchem) and spread with a sterile spatula. All the plates were incubated at $37^{\circ} \mathrm{C}$ for $48 \mathrm{~h}$. Grey-black shiny convex colonies of 1 to $1.5 \mathrm{~mm}$ in diameter (up to $3 \mathrm{~mm}$ ) with narrow white margins surrounded by a zone of clearing $(2-5 \mathrm{~mm})$ were identified as $S$. aureus and confirmed by hemolysis on blood agar (blood agar base added with defibrinated horse blood, Oxoid), coagulase, thermonuclease (TNase), and complementary biochemical tests with API 20 STAPH (BioMérieux, Marcy-l'Etoile, France). All gram-positive, catalasepositive, coagulase-positive, cocci that produced $\beta$-hemolysis on blood agar and TNase were identified as $S$. aureus and then tested with API 20 STAPH for confirmation. Selected colonies were subcultured into brain heart infusion (BHI) broth with $15 \%$ of glycerol (Bio-Rad, Hercules, CA) for $24 \mathrm{~h}$ at $37^{\circ} \mathrm{C}$ and then frozen at $-80^{\circ} \mathrm{C}$ for storage.

Coagulase determination was performed according to ISO standard 6888-1:1999 (ISO, 1999) using lyophilized rabbit plasma with EDTA (BBL Microbiology Systems, Cockeysville, MD) reconstituted with sterile water. Briefly, $0.1 \mathrm{~mL}$ of a BHI broth culture of presumed $S$. aureus colonies were inoculated into 5 -mL test tubes containing $0.3 \mathrm{~mL}$ of the reconstituted plasma. Complete clotting after incubation at $37^{\circ} \mathrm{C}$ within 4 to $24 \mathrm{~h}$ was regarded as a positive result.

The TNase production was determined according to the method described by Ibrahim et al. (1981). The isolates of $S$. aureus were thawed and cultivated in BHI broth (Bio-Rad) at $37^{\circ} \mathrm{C}$ for $48 \mathrm{~h}$. Cultures were placed into a water bath at $100^{\circ} \mathrm{C}$ for 15 min to eliminate any nonspecific, heat-labile, nuclease activity; they were then centrifuged at $3,000 \times g$ for 30 min at room temperature. Before testing, wells of $5 \mathrm{~mm}$ in diameter were prepared on plates containing TNase agar with toluidine blue, and then $90 \mu \mathrm{L}$ of supernatant was then transferred into each well and the plates were incubated at $45^{\circ} \mathrm{C}$ for $4 \mathrm{~h}$. The presence of a pink ring around the well was considered a positive result. 
The isolates of $S$. aureus were thawed and aerobically cultivated in BHI broth (Bio-Rad) at $37^{\circ} \mathrm{C}$ for $48 \mathrm{~h}$. Extraction of the DNA was then carried out using the DNeasy Blood and Tissue kit (Qiagen, Hiden, Germany). The DNA amplification was conducted on a volume of $25 \mu \mathrm{L}$ using $12.5 \mu \mathrm{L}$ of RED Taq $(10$ $\mathrm{m} M$ Tris $\mathrm{HCl} \mathrm{pH} 8.3,50 \mathrm{~m} M \mathrm{KCl}, 1.5 \mathrm{~m} M \mathrm{MgCl}_{2}$, $0.001 \%$ of gelatin, $0.2 \mathrm{mM}$ each deoxyribonucleoside triphosphate), $0.5 \mu \mathrm{L}(1 \mu M)$ of each primer, $5 \mu \mathrm{L}$ of extracted DNA, and $6.5 \mu \mathrm{L}$ of $\mathrm{H}_{2} \mathrm{O}$. The presence of the $n u c$, sea, seb, sec, sed, and see genes was investigated. The primers and the amplification conditions used are given in Table 1. The PCR reaction was carried out in a Thermocycler Gene Amp, PCR System, 9700 Gold (Applied Biosystem, Foster City, CA). The amplifications were analyzed by electrophoretic run on $1.5 \%$ agarose gel containing ethidium bromide $(0.5 \mu \mathrm{g} / \mathrm{mL})$; $10 \mu \mathrm{L}$ of each PCR sample was loaded with $2 \mu \mathrm{L}$ of $6 \times$ loading buffer (Fermentas, Thermo Fisher Scientific, Waltham, MA) and $5 \mu \mathrm{L}$ of marker PCR as reference DNA (Fermentas). The run was carried out at a voltage of $100 \mathrm{~V}$ for about $1 \mathrm{~h}$ in TBE $10 \times$ (Trizma base, boric acid, EDTA, Euroclone, Siziano, Italy; $0.5 M \mathrm{pH}$ 8). At the end of the run, the bands were viewed with the UV transilluminator (Fotodine 3-3102 Celbio, Milan, Italy).

The determination of enterotoxin production was made with the Ridascreen SET Total (R-Biopharm, Melegnano, Milan, Italy), an enzyme immunoassay for the combined detection of $S$. aureus enterotoxins A, B, C, D, and E not only in fluid and solid foods, but also in bacterial cultures. Staphylococcus aureus isolates and 3 internal control (strain 239 SEA and SEE producer, strain 27R SEB, SEC, and SED, and strain 38 SE-negative) were cultivated in $\mathrm{BHI}$ broth (Bio-Rad) at $37^{\circ} \mathrm{C}$ for $48 \mathrm{~h}$. Cultures were centrifuged at $3,500 \times g$ for 5 min at room temperature. One hundred microliters of the supernatant was transferred into each well. After the test procedure, a color change of the liquid in the well to yellow indicated the presence of enterotoxins. The positive isolates were tested using the Ridascreen SET A, B, C, D, and E (R-Biopharm) to identify the individual toxin.

The isolates were thawed and cultured in BHI broth (Bio-Rad) at 35 to $37^{\circ} \mathrm{C}$ for $24 \mathrm{~h}$. Part of the culture broth was inoculated into $6 \mathrm{~mL}$ of $0.9 \%$ sterile physiological saline solution until reaching a turbidity of 2 McFarland. Using a sterile swab, the solution thus obtained was seeded on Müller-Hinton agar (Oxoid). Disks containing antimicrobials (Oxoid) were placed on the plates, which were then incubated at 35 to $37^{\circ} \mathrm{C}$ for 18 to $24 \mathrm{~h}$ on air. The antimicrobials tested were ampicillin $10 \mu \mathrm{g}$, ciprofloxacin $5 \mu \mathrm{g}$, kanamycin $30 \mu \mathrm{g}$, tetracycline $30 \mu \mathrm{g}$, gentamicin $10 \mu \mathrm{g}$, methicillin $5 \mu \mathrm{g}$, nalidixic acid $30 \mu \mathrm{g}$, erythromycin $5 \mu \mathrm{g}$, amoxicillin/ clavulanic acid $30 \mu \mathrm{g}$, streptomycin $10 \mu \mathrm{g}$, vancomycin $30 \mu \mathrm{g}$, neomycin $30 \mu \mathrm{g}$, and enrofloxacin $5 \mu \mathrm{g}$. At the end of the incubation, the diameters of the growth inhibitory zones were measured and interpreted according to the Clinical and Laboratory Standards Institute guidelines (CLSI, 2011).

Tables 2 and 3 show the results. Eighty-seven cows were diagnosed as mastitic according to their SCC and plate count. Sixty isolates were presumptively identified as $S$. aureus based on cultural characteristics, 17 of which were confirmed as $S$. aureus by API 20 STAPH, TNase, and coagulase. Seven isolates were enterotoxin producers; all produced SEA, 1 produced SEB, 1 produced SEC, 5 produced SED, and 6 produced SEE. Confirmed $S$. aureus isolates were isolated from 6 farms. The 7 enterotoxin-producing $S$. aureus isolates came from 3 farms. The percentage of enterotoxin-producing isolates among confirmed $S$. aureus was $41.18 \%$ (41.18\% SEA, 5.88\% SEB and SEC, $29.41 \%$ SED, and $35.26 \%$ SEE).

All the 17 S. aureus isolates were confirmed as thermostable nuclease producers by PCR for nuc gene. The percentage of positive for the staphylococcal enterotoxin genes were $35.29 \%$ (6) sea gene, $5.88 \%$ (1) seb gene, $5.88 \%$ (1) sec gene, $29.41 \%$ (5) sed gene, and $47.06 \%$ (8) see gene. Six out of the 7 enterotoxin-producing isolates were capable of expressing the corresponding enterotoxin under the conditions tested. One isolate was positive for the production of SEA toxin, negative by PCR for the sea gene, and positive by PCR for the see gene. One isolate was positive at the PCR for the see gene and was negative at both the enzyme immunoassay diagnostic kit.

The antimicrobial susceptibility test data are shown in Table 4. All isolates were sensitive to ciprofloxacin, kanamycin, tetracycline, gentamicin, methicillin, vancomycin, neomycin, and enrofloxacin. None of the isolates were sensitive to nalidixic acid $(70.59 \%$ of the isolates were resistant, $29.41 \%$ were intermediate).

In the literature, despite the large number of works describing the prevalence of enterotoxin gene profiles from clinical and environmental $S$. aureus, information on the actual aptitude of strains associated with mastitic animals to produce SE is scarce. Few reports provide the actual enterotoxin production, such as the studies of Kenny et al. (1993), in which 72 out of $262(28.6 \%)$ of bovine mammary isolates of $S$. aureus producing at least 1 toxin, Matsunaga et al. (1993), in which the prevalence of enterotoxin-producing $S$. aureus was $34.5 \%$ (among 58 isolates), or Cenci-Goga et al. (2003), who found a prevalence of $13.8 \%$ (22 positives among 160 isolates). The methods used to identify $S$. aureus, along with misdiagnosis, improper sample collection, 
GRISPOLDI ET AL.

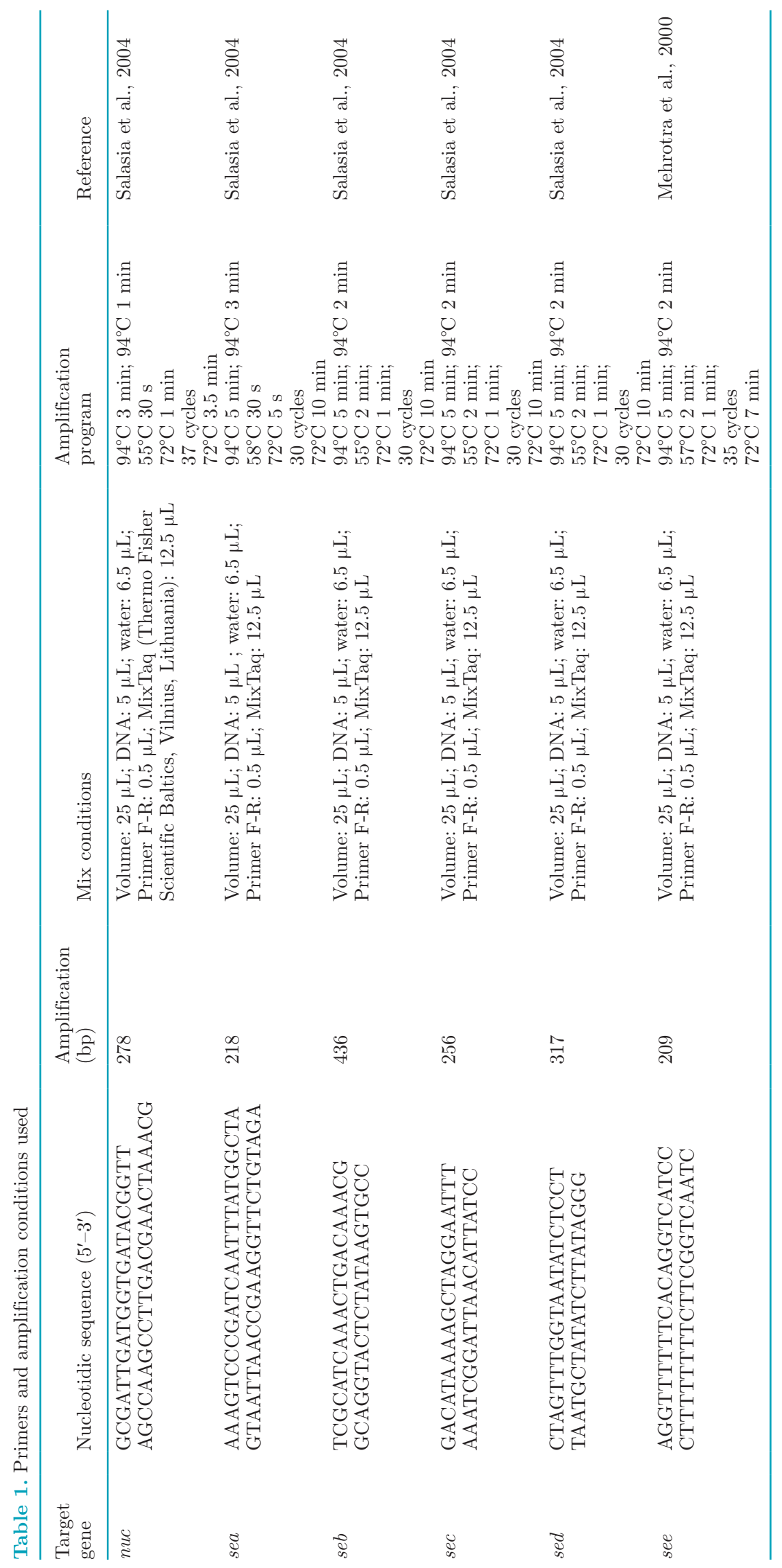


Table 2. Enterotoxin production by Staphylococcus aureus isolated at various dairy farms ${ }^{1}$

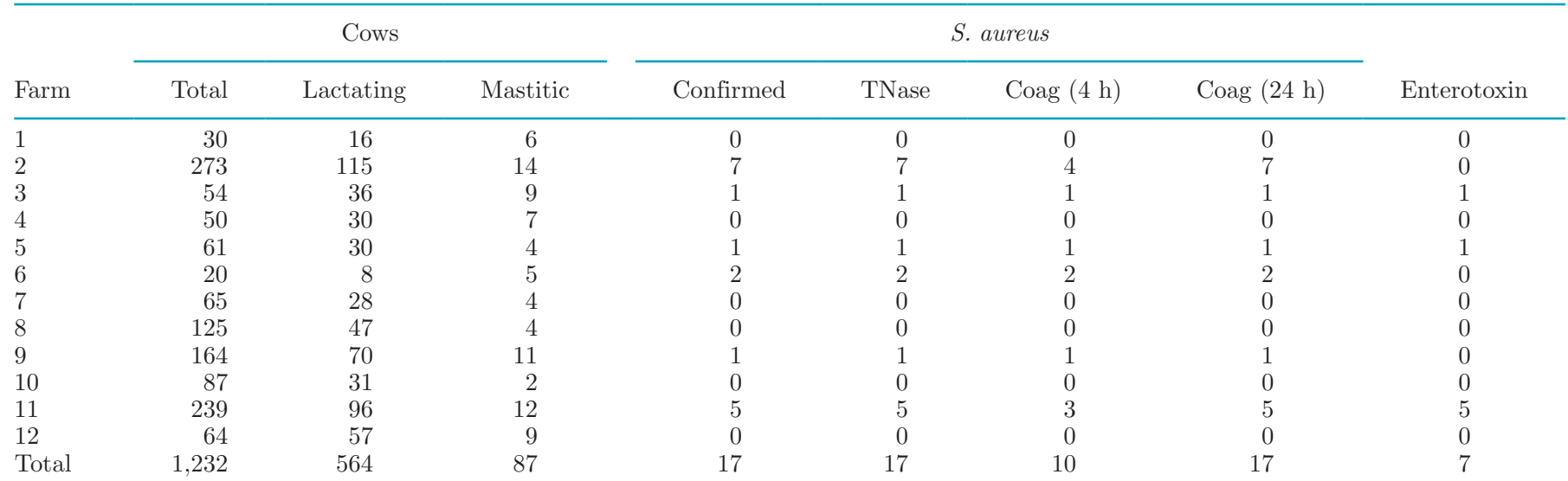

${ }^{1}$ Confirmed $=$ strains confirmed as $S$. aureus by hemolysis on blood agar, coagulase, TNase, and complementary biochemical tests with API 20 STAPH (BioMérieux, Marcy-l'Etoile, France); TNase = thermonuclease measured by enzyme activity; coag = coagulase measured by enzyme activity at 4 and $24 \mathrm{~h}$; enterotoxin = detectable enterotoxin produced in brain heart infusion broth (Bio-Rad, Hercules, CA) after $48 \mathrm{~h}$ at $37^{\circ} \mathrm{C}$.

and laboratory examination, can reflect the different proportion of isolates that produce SE (Kadariya et al., 2014).

Some authors have reported that the most common enterotoxins produced by $S$. aureus isolated from dairy products of bovine or ovine origin are SEC and SED (Cenci-Goga et al., 2003; Vitale et al., 2015, 2018). However, a recent study of Fursova et al. (2018) reported the production of SEA, SEC, SEE, and SEG in higher proportions by $S$. aureus isolated from subclinical mastitis. On the contrary, the most common enterotoxin produced by $S$. aureus involved in food poisoning outbreaks is SEA (Bastos et al., 2017). Many possible explanations exist for the different rates of enterotoxin production reported in the different studies (Cretenet et al., 2011). The fact that we found that 5 out of 7 of the enterotoxin-producing isolates produced SED, whereas only 1 out of 7 produced SEC, 6 out of 7 produced SEE, and all 7 produced SEA, is probably related to the differences in the ecological reservoir of $S$. aureus in different countries and regions of the world that could influence findings on the production of enterotoxin. The same variables can also influence the variability in the detection rates of the different types of staphylococcal enterotoxin (Birhanu et al., 2017). Lastly, the method used to detect the enterotoxin production could influence the results.

The enzyme immunoassay detection kit we used has a limit of detection for bacterial cultures of $0.25 \mathrm{ng} / \mathrm{mL}$ of toxin. Therefore, it seems very unlikely that some of the isolates analyzed produced undetectable levels of SE.

We noted two inconsistencies in our study. First, 1 isolate positive for the production of SEA toxin was negative by PCR for the sea gene but positive by PCR for the see gene; second, 1 isolate positive by PCR for the see gene was negative at the enzyme immunoassay diagnostic kit, confirming the fact that the presence of genes does not guarantee their expression under all conditions.

Although we characterized a limited number of isolates, very little antibiotic resistance was identified.

Table 3. Specific enterotoxins produced in brain heart infusion broth (Bio-Rad, Hercules, CA) after $48 \mathrm{~h}$ at $37^{\circ} \mathrm{C}$ (presence of the indicated genes determined by PCR in parentheses)

\begin{tabular}{lccccc}
\hline & \multicolumn{5}{c}{ Enterotoxin (genes) } \\
\cline { 2 - 5 } Isolate & $\mathrm{A}$ & $\mathrm{B}$ & $\mathrm{C}$ & $\mathrm{D}$ & $\mathrm{E}$ \\
\hline 1 & $+(+)$ & $+(+)$ & $+(+)$ & $-(-)$ & $+(+)$ \\
2 & $+(-)$ & $-(-)$ & $-(-)$ & $-(-)$ & $-(+)$ \\
3 & $+(+)$ & $-(-)$ & $-(-)$ & $+(+)$ & $+(+)$ \\
4 & $+(+)$ & $-(-)$ & $-(-)$ & $+(+)$ & $+(+)$ \\
5 & $+(+)$ & $-(-)$ & $-(-)$ & $+(+)$ & $+(+)$ \\
6 & $+(+)$ & $-(-)$ & $-(-)$ & $+(+)$ & $+(+)$ \\
7 & $+(+)$ & $-(-)$ & $-(-)$ & $+(+)$ & $+(+)$ \\
\hline
\end{tabular}


Table 4. Antimicrobial susceptibility test data

\begin{tabular}{lccc}
\hline Antimicrobial & $\begin{array}{c}\text { Resistant } \\
(\%)\end{array}$ & $\begin{array}{c}\text { Intermediate } \\
(\%)\end{array}$ & $\begin{array}{c}\text { Sensitive } \\
(\%)\end{array}$ \\
\hline Ampicillin $10 \mu \mathrm{g}$ & 52.94 & 0 & 47.06 \\
Ciprofloxacin $5 \mu \mathrm{g}$ & 0 & 0 & 100 \\
Kanamycin $30 \mu \mathrm{g}$ & 0 & 0 & 100 \\
Tetracycline $30 \mu \mathrm{g}$ & 0 & 0 & 100 \\
Gentamicin $10 \mu \mathrm{g}$ & 0 & 0 & 100 \\
Methicillin $5 \mu \mathrm{g}$ & 0 & 0 & 100 \\
Nalidixic acid $30 \mu \mathrm{g}$ & 70.59 & 29.41 & 0 \\
Erythromycin $5 \mu \mathrm{g}$ & 5.88 & 0 & 94.12 \\
Amoxicillin $/$ clavulanic acid $30 \mu \mathrm{g}$ & 17.65 & 0 & 82.35 \\
Streptomycin $10 \mu \mathrm{g}$ & 0 & 5.88 & 94.12 \\
Vancomycin $30 \mu \mathrm{g}$ & 0 & 0 & 100 \\
Neomycin $30 \mu \mathrm{g}$ & 0 & 0 & 100 \\
Enrofloxacin $5 \mu \mathrm{g}$ & 0 & 0 & 100 \\
\hline
\end{tabular}

The antimicrobial susceptibility test data showed that the isolates were sensitive to the main classes of antimicrobials used for the treatment of bovine mastitis, although none of the isolates was sensitive to nalidixic acid. With reference to antimicrobials used in humans, none of the isolates showed resistance to vancomycin and methicillin, which have been described in dairies (Bhattacharyya et al., 2016; Klibi et al., 2018).

The presence of enterotoxin-producing isolates of $S$. aureus in bovine milk means that a temperature abuse or a breakdown in the thermal treatment of the milk could present a food safety risk, particularly as all enterotoxigenic isolates could potentially produce SEA in milk. Moreover, the presence of SEA-producing isolates indicates that, to prevent potential food-borne staphylococcal intoxication, veterinary clinicians should make a greater effort to detect and prevent mastitis in dairy cattle in the interest of enhancing the control of potential food-borne staphylococcal intoxication.

\section{ACKNOWLEDGMENTS}

The authors express sincere appreciation to members of Polyglot, Perugia, Italy, for a careful reading and comments on the manuscript.

\section{REFERENCES}

Asao, T., Y. Kumeda, T. Kawai, T. Shibata, H. Oda, K. Haruki, H Nakazawa, and S. Kozaki. 2003. An extensive outbreak of staphylococcal food poisoning due to low-fat milk in Japan: estimation of enterotoxin A in the incriminated milk and powdered skim milk. Epidemiol. Infect. 130:33-40.

Bastos, C. P., M. T. Bassani, M. M. Mata, G. V. Lopes, and W. P. da Silva. 2017. Prevalence and expression of staphylococcal enterotoxin genes in Staphylococcus aureus isolated from food poisoning outbreaks. Can. J. Microbiol. 63:834-840.

Bhattacharyya, D., J. Banerjee, S. Bandyopadhyay, B. Mondal, P. K. Nanda, I. Samanta, A. Mahanti, A. K. Das, G. Das, P. Dandapat, and S. Bandyopadhyay. 2016. First Report on vancomycin-resistant Staphylococcus aureus in bovine and caprine milk. Microb. Drug Resist. 22:675-681.
Birhanu, M., S. Leta, G. Mamo, and S. Tesfaye. 2017. Prevalence of bovine subclinical mastitis and isolation of its major causes in Bishoftu Town, Ethiopia. BMC Res. Notes 10:767.

Cenci-Goga, B. T., M. Karama, P. V. Rossitto, R. A. Morgante, and J. S. Cullor. 2003. Enterotoxin production by Staphylococcus aureus isolated from mastitic cows. J. Food Prot. 66:1693-1696.

CLSI. 2011. Clinical and Laboratory Standards Institute Guidelines, 2011. Clinical and Laboratory Standards Institute (CLSI), Wayne, PA.

Cretenet, M., S. Even, and Y. Le Loir. 2011. Unveiling Staphylococcus aureus enterotoxin production in dairy products: A review of recent advances to face new challenges. Dairy Sci. Technol. 91:127-150.

Denayer, S., L. Delbrassinne, Y. Nia, and N. Botteldoorn. 2017. Foodborne outbreak investigation and molecular typing: High diversity of Staphylococcus aureus strains and importance of toxin detection. Toxins (Basel) 9:E407.

European Food Safety Agency and European Centre for Disease Prevention and Control. 2016. The European Union summary report on trends and sources of zoonoses, zoonotic agents and food-borne outbreaks in 2015. EFSA J. 14:1-231. https://doi.org/10.2903/j .efsa.2016.4634

Fursova, K. K., M. P. Shchannikova, I. V. Loskutova, A. O. Shepelyakovskaya, A. G. Laman, A. M. Boutanaev, S. L. Sokolov, O. A Artem'eva, D. A. Nikanova, N. A. Zinovieva, and F. A. Brovko. 2018. Exotoxin diversity of Staphylococcus aureus isolated from milk of cows with subclinical mastitis in Central Russia. J. Dairy Sci. 101:4325-4331.

Hait, J. M., S. M. Tallent, and R. W. Bennett. 2014. Screening, detection, and serotyping methods for toxin genes and enterotoxins in Staphylococcus strains. J. AOAC Int. 97:1078-1083.

Hennekinne, J. A., M. L. De Buyser, and S. Dragacci. 2012. Staphylococcus aureus and its food poisoning toxins: Characterization and outbreak investigation. FEMS Microbiol. Rev. 36:815-836.

Ibrahim, G. F., A. K. Baldock, D. R. Radford, and L. B. Ireland. 1981. Inhibition of Staphylococcus aureus growth and enterotoxin-A production in Cheddar cheese produced with variable starter activity. J. Food Prot. 44:263-267.

Ikeda, T., N. Tamate, K. Yamaguchi, and S.-I. Makino. 2005. Mass outbreak of food poisoning disease caused by small amounts of staphylococcal enterotoxins A and H. Appl. Environ. Microbiol. 71:2793-2795

ISO. 1999. ISO standard 6888-1:1999 Microbiology of food and animal feeding stuffs - Horizontal method for the enumeration of coagulase-positive staphylococci (Staphylococcus aureus and other species) - Part 1: Technique using Baird-Parker agar medium. International Organization for Standardization, Geneva, Switzerland.

Kadariya, J., T. C. Smith, and D. Thapaliya. 2014. Staphylococcus aureus and staphylococcal food-borne disease: An ongoing challenge in public health. BioMed Res. Int. 2014:827965. 
Kenny, K., R. F. Reiser, F. D. Bastida-Corcuera, and N. L. Norcross. 1993. Production of enterotoxins and toxic shock syndrome toxin by bovine mammary isolates of Staphylococcus aureus. J. Clin. Microbiol. 31:706-707.

Kérouanton, A., J. A. Hennekinne, C. Letertre, L. Petit, O. Chesneau, A. Brisabois, and M. L. De Buyser. 2007. Characterization of Staphylococcus aureus strains associated with food poisoning outbreaks in France. Int. J. Food Microbiol. 115:369-375.

Klibi, A., A. Jouini, P. Gomez, K. Slimene, S. Ceballos, C. Torres, and A. Maaroufi. 2018. Molecular characterization and clonal diversity of methicillin-resistant and -susceptible Staphylococcus aureus isolates of milk of cows with clinical mastitis in Tunisia. Microb. Drug Resist. 24:1210-1216. https://doi.org/10.1089/mdr.2017.0278.

Matsunaga, T., S. Kamata, N. Kilkiichi, and K. Uchida. 1993. Characteristics of Staphylococcus aureus isolated from peracute, acute and chronic bovine mastitis. J. Vet. Med. Sci. 55:297-300.

Mehrotra, M., G. Wang, and W. M. Johnson. 2000. Multiplex PCR for detection of genes for Staphylococcus aureus enterotoxins, exfoliative toxins, toxic shock syndrome toxin 1 , and methicillin resistance. J. Clin. Microbiol. 38:1032-1035.

Nia, Y., I. Mutel, A. Assere, B. Lombard, F. Auvray, and J. A. Hennekinne. 2016. Review over a 3-year period of European Union Proficiency tests for detection of staphylococcal enterotoxins in food matrices. Toxins (Basel) 8:107.

Ono, H. K., Y. Sato'o, K. Narita, I. Naito, S. Hirose, J. Hisatsune, K. Asano, D. L. Hu, K. Omoe, M. Sugai, and A. Nakane. 2015. Iden- tification and characterization of a novel staphylococcal emetic toxin. Appl. Environ. Microbiol. 81:7034-7040.

Ostyn, A., M. L. De Buyser, F. Guillier, J. Groult, B. Felix, S. Salah, G. Delmas, and J. A. Hennekinne. 2010. First evidence of a food poisoning outbreak due to staphylococcal enterotoxin type E, France, 2009. Euro. Surveill. 15:19528.

Salasia, S. I., Z. Khusnan, C. Lammler, and M. Zschock. 2004. Comparative studies on pheno- and genotypic properties of Staphylococcus aureus isolated from bovine subclinical mastitis in central Java in Indonesia and Hesse in Germany. J. Vet. Sci. 5:103-109.

Schelin, J., Y. B. Susilo, and S. Johler. 2017. Expression of staphylococcal enterotoxins under stress encountered during food production and preservation. Toxins (Basel) 9:E401.

Vitale, M., S. Gaglio, P. Galluzzo, G. Cascone, C. Piraino, V. Di Marco Lo Presti, and R. Alduina. 2018. Antibiotic resistance profiling, analysis of virulence aspects and molecular genotyping of Staphylococcus aureus isolated in Sicily, Italy. Foodborne Pathog. Dis. 15:177-185.

Vitale, M., M. L. Scatassa, C. Cardamone, G. Oliveri, C. Piraino, R. Alduina, and C. Napoli. 2015. Staphylococcal food poisoning case and molecular analysis of toxin genes in Staphylococcus aureus strains isolated from food in Sicily, Italy. Foodborne Pathog. Dis. $12: 21-23$. 